\title{
Capacity balancing for vanadium redox flow batteries through continuous and dynamic electrolyte overflow
}

\author{
Katharina Schafner ${ }^{1,2}$ (D) Maik Becker ${ }^{1,2}$ (D) Thomas Turek $^{1,2}$ (D)
}

Received: 31 July 2020 / Accepted: 20 April 2021 / Published online: 13 May 2021

(C) The Author(s) 2021

\begin{abstract}
The vanadium crossover through the membrane can have a significant impact on the capacity of the vanadium redox flow battery (VFB) over long-term charge-discharge cycling. The different vanadium ions move unsymmetrically through the membrane and this leads to a build-up of vanadium ions in one half-cell with a corresponding decrease in the other. In this paper, a dynamic model is developed based on different crossover mechanisms (diffusion, migration and electro osmosis) for each of the four vanadium ions, water and protons in the electrolytes. With a simple to use approach, basic mass transport theory is used to simulate the transfer of vanadium ions in the battery. The model is validated with own measurements and can therefore predict the battery capacity as a function of time. This is used to analyse the battery performance by applying an overflow from one half-cell to the other. Different constant overflow rates were analysed with regard to an impact of the performance and electrolyte stability. It was observed that a continuous overflow increases the capacity significantly but that the electrolyte stability plays an essential role using a membrane with a big vanadium crossover. Even with a good performance, a complete remixing of the tanks is necessary to prevent electrolyte precipitations. Therefore, a dynamic overflow was determined in such a way that the capacity of the battery is maximised while the electrolytes remain stable for 200 cycles.
\end{abstract}

\section{Graphic abstract}
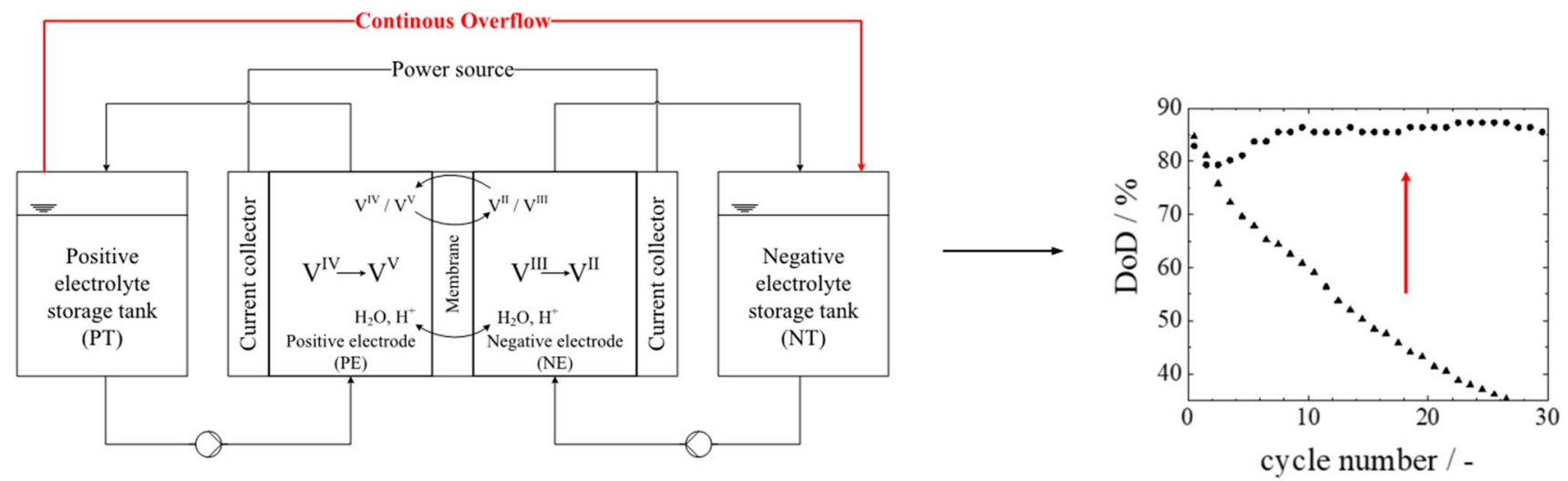

Keywords Vanadium redox flow battery $\cdot$ Mathematical model $\cdot$ Crossover $\cdot$ Self-discharge $\cdot$ Capacity balancing

Maik Becker

maik.becker@tu-clausthal.de

$1 \quad$ Institute of Chemical and Electrochemical Process Engineering, Clausthal University of Technology, Leibnizstr. 17, 38678 Clausthal-Zellerfeld, Germany

2 Research Center for Energy Storage Technologies (EST), Am Stollen 19A, 38640 Goslar, Germany

\section{Introduction}

The vanadium redox flow battery (VFB) is an attractive storage technology for large-scale storage applications because of its decoupled power and energy rating. As for almost all rechargeable batteries, VFB encounter the problem of capacity loss after a certain duration of charge-discharge 
operation. The main reason for the capacity loss is the vanadium crossover through the membrane which leads to a continuous self-discharge of the battery [1-3]. The primary task of the membrane is to separate the half-cells and let protons (in case of a cation exchange membranes) pass due to charge balance during charging and discharging. Nevertheless, vanadium ions are able to move from one half-cell to the other which results in self-discharge reactions in the electrolytes. Concentration gradients, pressure difference and potential difference at the membrane are the driving forces for the crossover mechanisms diffusion, migration and convection (electro osmosis and hydraulic convection) [4-11]. While the hydraulic pressure difference is caused by the cell design and can thus theoretically be eliminated with an optimized cell concept, the other three mechanisms are always present during an operating battery. Moreover, an unsymmetrical movement of the vanadium ions results in an enrichment of vanadium ions in one half-cell and in a dilution in the other. This results in a continuous decrease of capacity in the VFB, i.e. a decreasing depth of discharge (DoD) [12]. All the charged ions drag a water shell while crossing the membrane, which additionally leads to a volume drift towards one half-cell $[9,13]$.

Until now there are only a few papers which describe the crossover during cycling experimentally [14-16] or based on a mathematical model [1, 4, 17-21]. A dynamic model for the cell potential was developed by Tang et al. [1] to simulate the capacity loss caused by diffusion of the four vanadium species in a VFB for three different membranes. The diffusion process was described using diffusion coefficients reported in literature. The potential was calculated using a modified Nernst equation. Up to 200 charge-discharge cycles were simulated for a potential range from $1.1 \mathrm{~V}$ for the discharge process to $1.7 \mathrm{~V}$ for the charge process. The temperature, cell resistance and tank volumes were assumed to be constant. Although, only the diffusion process was considered, a significant loss in capacity was observed. Skyllas-Kazacos and Goh [19] studied the influence of current and mass transfer coefficients on the diffusion process and the long-term performance of the VFB using a model based on mass balances for the active species. The model predicts that regarding only the diffusion process, a steady state vanadium ion concentration will be reached after a certain number of cycles. The diffusion and migration process was studied by Won et al. [20] using a dynamic 3-D model. The model describes the diffusion and migration crossover and side reactions in each electrode. The crossover mass fluxes are calculated using the Nernst-Planck equation. The results show the capacity losses due to the crossover and moreover, a degradation of the membrane was calculated assuming that the crossover diffusivity of each vanadium ion through the membrane is ten times higher than those of fresh membranes. A dynamic model describing the three different transport processes through the membrane (diffusion, migration and convection) were developed by Darling et al. (zero-dimensional) [4], Boettcher et al. (zero-dimensional) [17] and Knehr et al. (two-dimensional) [18] using the Nernst-Planck equation. The Nernst-Planck equation defines the species movement through the membrane due to diffusion, migration and convection. To use this equation many parameters have to be utilized as for example the ionic potential, the ionic mobility, the species concentrations in the membrane and the boundary layer thickness between the membrane and the bulk electrolyte.

A more recent work of Shirasaki and Yamamura evaluated the reliability of a frequently applied method to determine diffusion coefficients of vanadium species across the membrane. These authors evaluated permeability tests with ${ }^{48} \mathrm{~V}$ as a radiotracer, though the permeability test could be conducted with vanadium electrolyte on both sides of the membrane with one electrolyte side containing the radioactive ${ }^{48} \mathrm{~V}$ isotope. Their results indicated significant differences to usually applied permeability tests with vanadium electrolyte on one side (donor) and magnesium sulfate, diluted sulfuric acid solutions on the other (acceptor) side of the membrane. However, VFBs are operated with vanadium electrolyte on both sides, thus Shirasaki and Yamamura's results emphasize the need to determine membrane parameters under operating conditions as close to real VFBs as possible. Crothers et al. developed a quite complex model for transport processes within a cation exchange membrane of a VFB based on Stefan-Maxwell-Onsager theory [22]. Their model can predict concentration profiles within the membrane and resulting mass fluxes through the membrane presenting valuable insights into interactions between different species within the membrane. However, a large number of only indirectly accessible parameters is required and self-discharge redox reactions within the membrane are not implemented. Kim et al. analysed the transport phenomena during crossover processes in a VFB membrane by application of a zero-dimensional model incorporating diffusion, osmosis, convection and self-discharge reactions. However, the main focus was put on electrolyte volume changes with model validations carried out for the 3rd and 300th cycle [23].

In this work, the number of unknown parameters is minimized by utilizing only one mass transfer coefficient for each crossover mechanism to describe the crossover process. The model is validated with own measurements during charge-discharge cycling operation and can predict the species crossover and the resulting capacity loss sufficiently well. This paper describes a zero-dimensional model of the concentration and volume changes in a VFB using the cation exchange membrane Nafion ${ }^{\mathrm{TM}} \mathrm{N} 117$ from Chemours. The model can be used to simulate the long-term behaviour of the VFB. Moreover, a capacity balancing method using a 
continuous overflow from one half-cell to other is implemented in the model. Different overflow rates were analysed to determine the best battery operation regarding the performance and electrolyte stability. The prediction of capacity and electrolyte stability is very important to assist in the development of a control system for the VFB to ensure the best possible long-term performance.

\section{Model development}

The model is divided in five sub models: the positive electrolyte storage tank (PT), the positive electrode (PE), the membrane, the negative electrode (NE) and the negative electrolyte storage tank (NT). The electrolytes in the tanks and electrodes consist of water, sulfuric acid and $\mathrm{VO}^{2+}\left(\mathrm{V}^{\mathrm{IV}}\right)$ as well as $\mathrm{VO}_{2}{ }^{+}\left(\mathrm{V}^{\mathrm{V}}\right)$ in PT and $\mathrm{PE}$ or $\mathrm{V}^{2+}\left(\mathrm{V}^{\mathrm{II}}\right)$ and $\mathrm{V}^{3+}$ $\left(\mathrm{V}^{\mathrm{III}}\right)$ ions in NT and NE, respectively (Fig. 1). All the submodels and the resulting overall model, were embedded in MATLAB R2018a and the solver "ode15s" was applied to solve the set of equations.

For the model, the following assumptions are made:

- All sub models are considered isothermal.

- The electrolyte is assumed to be incompressible.

- The model is 0-dimensional: concentration gradients in any direction are neglected.

- The tanks and electrodes are considered as ideal stirred tank reactors.

- The tanks are only coupled with the corresponding electrode.

- The electrodes are coupled via the membrane.

- The electrodes have identical volume and porosity.

- No hydrogen and oxygen evolution reactions during charging occur.

- All reactions are assumed to take place instantaneously.
- The membrane exhibits a constant resistance during charge and discharge.

- No electrochemical reactions occur in the tanks.

\section{Electrolyte storage tank}

The electrolyte stored in the tanks consists of the species $\mathrm{H}_{2} \mathrm{O}, \mathrm{H}^{+}, \mathrm{SO}_{4}{ }^{2-}$ and $\mathrm{V}^{2+}, \mathrm{V}^{3+}$ for the negative electrolyte storage tank and $\mathrm{VO}^{2+}$ and $\mathrm{VO}_{2}^{+}$for the positive electrolyte storage tank, respectively. The species concentration and the volume in the tanks change during the operation of the battery due to electrolyte changes in the cell caused by electrochemical reactions and crossover. The concentration and volume change as well as the state of charge (SoC) are described using the following equations:

$c_{i}^{\text {out }}=\frac{n_{i}}{V_{\text {Tank }}}$

$\frac{d n_{i}}{d t}=\dot{V} \cdot\left(c_{i}^{\text {in }}-c_{i}^{\text {out }}\right)$

$V_{\mathrm{Tank}}=\sum_{i} \frac{n_{i} \cdot M_{i}}{\rho_{\mathrm{El}}}$

$S o C_{\mathrm{NE}}=\frac{c_{\mathrm{V} 2}^{\text {out }}}{c_{\mathrm{V} 2}^{\text {out }}+c_{\mathrm{V} 3}^{\text {out }}}$

$S o C_{\mathrm{PE}}=\frac{c_{\mathrm{V} 5}^{\text {out }}}{c_{\mathrm{V} 4}^{\text {out }}+c_{\mathrm{V} 5}^{\text {out }}}$

here $c_{i}{ }^{\text {out }}$ is the concentration of species $i$ in the electrolyte leaving the tank, $n_{i}$ the amount of species $i$ in the tank, $V_{\text {Tank }}$
Fig. 1 Schematic of the VFB and modelled domains

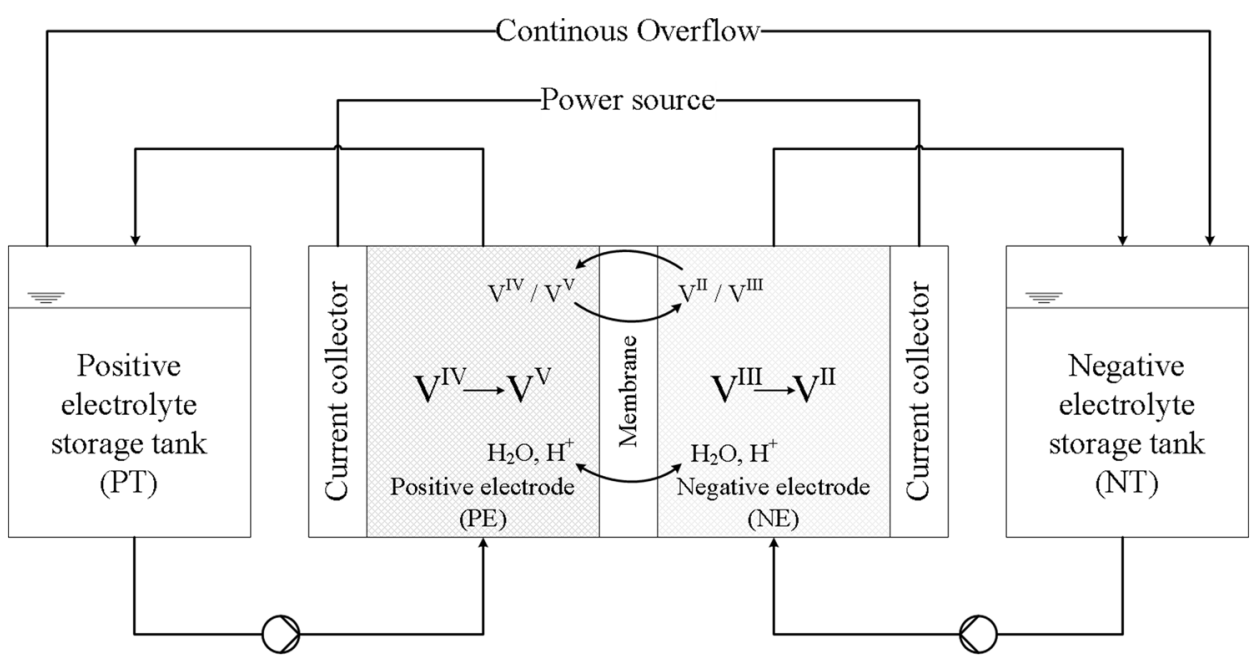


the tank volume, $\dot{V}$ the volume flow rate, $c_{i}^{\text {in }}$ the species concentration entering the tank, $M_{i}$ the molar mass of species $i$ and $\rho_{\mathrm{El}}$ the electrolyte density, which is considered to be constant $\left(1350 \mathrm{~kg} \mathrm{~m}^{-3}\right)$.

\subsection{Membrane}

The sub model for the membrane is used to describe the crossover fluxes of the species $\mathrm{V}^{2+}, \mathrm{V}^{3+}, \mathrm{VO}^{2+}, \mathrm{VO}_{2}{ }^{+}, \mathrm{H}^{+}$, $\mathrm{H}_{2} \mathrm{O}$ through the membrane. The crossover is caused by three mechanisms of species transport through the membrane: electro osmosis, diffusion and migration. The mechanisms are described with simple equations using a suitable transport coefficient multiplied by the driving force. Protons, additionally, move through the membrane due to charge balancing during operation. Therefore, the crossover mechanisms are not calculated for this species. At any time, the charge between the negative and positive electrode is assumed to be balanced due to proton movement. Additionally, each crossing charged species drags water with it through the membrane as water shell [9]. For the membrane sub model, the following additional assumptions are made:

- The membrane is hydraulically impermeable.

- No reaction takes place in the membrane.

- Sulphate ions do not move through the membrane.

- The species concentrations at the membrane surface area are equal to the bulk concentrations in the electrode.

- The electrical membrane resistance remains constant during operation.

- There is no interaction between the vanadium species moving through the membrane.

- The species crossover from PE to NE is defined as positive.

The potential difference $\Delta \varphi$ at the membrane is calculated from Ohm's law as follows:

$\Delta \varphi=j \cdot d_{\mathrm{Mem}} \cdot R_{\mathrm{Mem}}$

where $d_{\text {Mem }}$ is the membrane thickness and $R_{\text {Mem }}$ the specific membrane resistance $(0.38 \Omega \mathrm{m}$, from own measurements $[24,25])$. For the electro osmosis, the electrolyte velocity $u^{\text {eosm }}$ is calculated by multiplying the driving force (potential difference in Eq. (7)) with the mass transfer coefficient $k^{\text {eosm }}$ as shown below:

$u^{\mathrm{eosm}}=\Delta \varphi \cdot k^{\mathrm{eosm}}$

The diffusion through the membrane is described using Fick's law. The used mass transfer coefficients for diffusion $k_{i}^{\text {diff }}$ come from own measurements for the vanadium species [24]. The diffusion flux $N_{i}^{\text {diff }}$ is described for each species $i$ $\left(\mathrm{V}^{2+}, \mathrm{V}^{3+}, \mathrm{VO}^{2+}, \mathrm{VO}_{2}{ }^{+}, \mathrm{H}_{2} \mathrm{O}\right)$ using the following equation
$N_{i}^{\mathrm{diff}}=k_{i}^{\mathrm{diff}} \cdot\left(c_{i}^{\mathrm{pos}}-c_{i}^{\mathrm{neg}}\right) \cdot A_{\text {cross }}$

where $c_{i}$ is the concentration in the electrode in the positive or negative electrode and $A_{\text {cross }}$ the cross-sectional membrane area.

For both, crossover due to migration and electro osmosis, the direction of flux depends on the potential i.e. charge $(\Delta \varphi$ $<0)$ or discharge $(\Delta \varphi>0)$. During discharge the species move from the negative electrode to the positive electrode:

$N_{i}^{\mathrm{migr}}=c_{i}^{\mathrm{neg}} \cdot \Delta \varphi \cdot k_{i}^{\mathrm{migr}} \cdot A_{\text {cross }}$

$N_{i}^{\text {eosm }}=c_{i}^{\text {neg }} \cdot u^{\text {eosm }} \cdot A_{\text {cross }}$

whereas during charge the flux goes from the positive to the negative electrode:

$N_{i}^{\mathrm{migr}}=c_{i}^{\mathrm{pos}} \cdot \Delta \varphi \cdot k_{i}^{\mathrm{migr}} \cdot A_{\text {cross }}$

$N_{i}^{\mathrm{eosm}}=c_{i}^{\mathrm{pos}} \cdot u^{\mathrm{eosm}} \cdot A_{\text {cross }}$

The total flux of each species is defined as the sum of species movement due to electro osmosis, migration and diffusion:

$N_{i}^{\mathrm{Mem}}=N_{i}^{\mathrm{eosm}}+N_{i}^{\mathrm{migr}}+N_{i}^{\mathrm{diff}}$.

\subsection{Electrode}

Each half-cell consists of vanadium $\left(\mathrm{V}^{2+} / \mathrm{V}^{3+}\right.$ or $\mathrm{VO}^{2+} /$ $\mathrm{VO}_{2}{ }^{+}$), water and sulfuric acid. The electrolyte is pumped through the half-cells and the active species reacts during charge/discharge at a porous carbon electrode. The mass balance for each species is described as shown below:

$V_{\text {cell }} \cdot \frac{d c_{i}^{\text {out }}}{d t}=\dot{V} \cdot\left(c_{i}^{\text {in }}-c_{i}^{\text {out }}\right)+S_{i}$

with

$V_{\text {cell }}=A_{\text {cross }} \cdot d_{\text {electrode }} \cdot \varepsilon_{\text {electrode }}$

where $V_{\text {cell }}$ is the volume in the half-cell, $d_{\text {electrode }}$ the electrode thickness, $\varepsilon_{\text {electrode }}$ the porosity of the electrode and $S_{i}$ the source term for each species. The source term describes the change in species quantities mainly due to the electrochemical reactions (described with Faraday's law) in the half-cells, but also due to crossover.

During charge the following redox reactions occur in the half-cells:

$\mathrm{NE}: \mathrm{V}^{3+}+\mathrm{e}^{-} \rightarrow \mathrm{V}^{2+}$

$\mathrm{PE}: \mathrm{VO}^{2+}+\mathrm{H}_{2} \mathrm{O} \rightarrow \mathrm{VO}_{2}{ }^{+}+\mathrm{e}^{-}+2 \mathrm{H}^{+}$ 
The vanadium crossover causes the following discharge reactions in the half-cells:

$\mathrm{NE}: \mathrm{VO}^{2+}+\mathrm{V}^{2+}+2 \mathrm{H}^{+} \rightarrow 2 \mathrm{~V}^{3+}+\mathrm{H}_{2} \mathrm{O}$

$\mathrm{VO}_{2}^{+}+2 \mathrm{~V}^{2+}+4 \mathrm{H}^{+} \rightarrow 3 \mathrm{~V}^{3+}+\mathrm{H}_{2} \mathrm{O}$

$\mathrm{PE}: \mathrm{V}^{2+}+2 \mathrm{VO}_{2}^{+}+2 \mathrm{H}^{+} \rightarrow 3 \mathrm{VO}^{2+}+\mathrm{H}_{2} \mathrm{O}$

$\mathrm{V}^{3+}+\mathrm{VO}_{2}^{+} \rightarrow 2 \mathrm{VO}^{2+}$

Equations (18) to (21) describe that the charged species ( $\mathrm{V}^{\mathrm{II}}$ in $\mathrm{NE}$ and $\mathrm{V}^{\mathrm{V}}$ in $\mathrm{PE}$ ) reacts with the crossing species from the opposite half-cell. The source terms for concentration changes in the negative half-cell are described as follows:

$S_{\mathrm{V} 2}=\frac{-j \cdot A_{\text {cross }}}{\mathrm{F}}+N_{\mathrm{V} 2}^{\mathrm{Mem}}-2 N_{\mathrm{V} 5}^{\mathrm{Mem}}-N_{\mathrm{V} 4}^{\mathrm{Mem}}$

$S_{\mathrm{V} 3}=\frac{j \cdot A_{\text {cross }}}{\mathrm{F}}+N_{\mathrm{V} 3}^{\mathrm{Mem}}+3 N_{\mathrm{v} 5}^{\mathrm{Mem}}+2 N_{\mathrm{V} 4}^{\mathrm{Mem}}$

$S_{\mathrm{H}+}=N_{\mathrm{H}+}^{\mathrm{Mem}}-4 N_{\mathrm{V} 4}^{\mathrm{Mem}}-2 N_{\mathrm{V} 5}^{\mathrm{Mem}}$

$S_{\mathrm{H} 2 \mathrm{O}}=N_{\mathrm{H} 2 \mathrm{O}}^{\mathrm{Mem}}+2 N_{\mathrm{V} 5}^{\mathrm{Mem}}+N_{\mathrm{V} 4}^{\mathrm{Mem}}+\sum_{i} N_{i}^{\mathrm{Mem}} \cdot v_{i, \mathrm{H} 2 \mathrm{O}}^{\mathrm{drag}}$

here $v_{i, \mathrm{H} 2 \mathrm{O}}^{\text {drag }}$ is the amount of water dragged by species $i$ $\left(v_{V 2, \mathrm{H}_{2} \mathrm{O}}^{\text {drag }}=6, v_{V 3, \mathrm{H}_{2} \mathrm{O}}^{\text {drag }}=6, v_{V 4, \mathrm{H}_{2} \mathrm{O}}^{\text {drag }}=5, v_{V 5, \mathrm{H}_{2} \mathrm{O}}^{\text {drag }}=4, v_{\mathrm{H}, \mathrm{H}_{2} \mathrm{O}}^{\text {drag }}\right)$ [9], while $\mathrm{V} 4$ is the species $\mathrm{VO}^{2+}$ and $\mathrm{V} 5$ is $\mathrm{VO}_{2}{ }^{+}$, respectively. The parameter $v_{\mathrm{H}+\mathrm{H}_{2} \mathrm{O}}^{\mathrm{drag}}$ was adapted during the validation process.

The source term for concentration changes results in the positive half-cell to:

$$
\begin{aligned}
& S_{\mathrm{V} 4}=\frac{j \cdot A_{\text {cross }}}{F}-N_{\mathrm{V} 4}^{\mathrm{Mem}}-3 N_{\mathrm{V} 2}^{\mathrm{Mem}}-2 N_{\mathrm{V} 3}^{\mathrm{Mem}} \\
& S_{\mathrm{V} 5}=\frac{-j \cdot A_{\text {cross }}}{\mathrm{F}}-N_{\mathrm{V} 5}^{\mathrm{Mem}}+2 N_{\mathrm{V} 2}^{\mathrm{Mem}}+N_{\mathrm{V} 3}^{\mathrm{Mem}} \\
& S_{\mathrm{H}+}=\frac{-2 j \cdot A_{\text {cross }}}{\mathrm{F}}-N_{\mathrm{H}+}^{\mathrm{Mem}}+2 N_{\mathrm{V} 2}^{\mathrm{Mem}} \\
& S_{\mathrm{H}^{2} \mathrm{O}}=\frac{j \cdot A_{\text {cross }}}{\mathrm{F}}-N_{\mathrm{H}^{2} \mathrm{O}}^{\mathrm{Mem}}-2 N_{\mathrm{V} 2}^{\mathrm{Mem}}-\sum_{i} N_{i}^{\mathrm{Mem}} \cdot v_{i, \mathrm{H}^{2} \mathrm{O}}^{\text {drag }}
\end{aligned}
$$

\subsection{Continuous overflow from one tank to the other}

With regard to capacity balancing, a continuous overflow from PT to NT is implemented in the sub models of the tanks. Equation (2) is extended with the outgoing or incoming mass flow and the self-discharge reactions taking place in the NT [Eqs. (30) to (35)].

For PT:

$\frac{d n_{i}}{d t}=\dot{V} \cdot\left(c_{i}^{\text {in }}-c_{i}^{\text {out }}\right)-\dot{V}_{\text {rebal }} \cdot c_{i}^{\text {rebal }}$

For NT:

$\frac{d n_{V 2}}{d t}=\dot{V} \cdot\left(c_{V 2}^{\text {in }}-c_{V 2}^{\text {out }}\right)+\dot{V}_{\text {rebal }} \cdot\left(c_{V 2}^{\text {rebal }}-c_{V 4}^{\text {rebal }}-2 c_{V 5}^{\text {rebal }}\right)$

$\frac{d n_{V 3}}{d t}=\dot{V} \cdot\left(c_{V 3}^{\text {in }}-c_{V 3}^{\text {out }}\right)+\dot{V}_{\text {rebal }} \cdot\left(c_{V 3}^{\text {rebal }}+2 c_{V 4}^{\text {rebal }}+3 c_{V 5}^{\text {rebal }}\right)$

$\frac{d n_{\mathrm{H}+}}{d t}=\dot{V} \cdot\left(c_{\mathrm{H}+}^{\text {in }}-c_{\mathrm{H}+}^{\text {out }}\right)+\dot{V}_{\text {rebal }} \cdot\left(c_{\mathrm{H}+}^{\text {rebal }}-2 c_{V 4}^{\text {rebal }}-4 c_{V 5}^{\text {rebal }}\right)$

$\frac{d n_{\mathrm{H}_{2} \mathrm{O}}}{d t}=\dot{V} \cdot\left(c_{\mathrm{H}_{2} \mathrm{O}}^{\text {in }}-c_{\mathrm{H}_{2} \mathrm{O}}^{\text {out }}\right)+\dot{V}_{\text {rebal }} \cdot\left(c_{\mathrm{H}_{2} \mathrm{O}}^{\text {rebal }}+c_{V 4}^{\text {rebal }}+2 c_{V 5}^{\text {rebal }}\right)$

$\frac{d n_{\mathrm{SO}_{4}}}{d t}=\dot{V} \cdot\left(c_{\mathrm{SO}_{4}}^{\text {in }}-c_{\mathrm{SO}_{4}}^{\text {out }}\right)+\dot{V}_{\text {rebal }} \cdot c_{\mathrm{SO}_{4}}^{\text {rebal }}$.

\section{Experimental}

The model was validated with measurements on a test facility which has an online recording of several process variables such as current, cell voltage, volume flow rate, tank volume, electrolyte conductivity, pressure directly before and after the cell, as well as temperature in the tanks and in the cell. The cell was operated for ten charge-discharge cycles with a current density of $1000 \mathrm{~A} \mathrm{~m}^{-2}$. The limit for charge/discharge was the cell voltage, which was set to $0.8 \mathrm{~V}$ for the discharge process and to $1.8 \mathrm{~V}$ for the charge process, respectively.

The cell has an active area $\left(\mathrm{A}_{\text {cross }}\right)$ of $0.01 \mathrm{~m}^{2}$, carbon electrodes with a thickness of $0.95 \cdot 10^{-3} \mathrm{~m}$ and a porosity of 0.93 (GFD1.5 EA carbon felt from SGL Carbon GmbH, Germany; compression of $37 \%)$. The electrolyte $\left(1.6 \mathrm{~mol} \mathrm{~L}^{-1}\right.$ vanadium concentration and $4 \mathrm{~mol} \mathrm{~L}^{-1}$ total sulphate concentration) was purchased from GfE (Gesellschaft für Elektrometallurgie, Germany) and was pumped through each half-cell with a flow rate of $400 \mathrm{~mL} \mathrm{~min}^{-1}$ which corresponds to a flow velocity through the electrode of $2.9 \mathrm{~cm} \mathrm{~s}^{-1}$. 
It was found by Watt-Smith et al. that mean linear electrolyte velocities through the carbon felt electrode in a range of $1 \mathrm{~cm} \mathrm{~s}^{-1}$ to $10 \mathrm{~cm} \mathrm{~s}^{-1}$ are suitable [26]. The membrane Nafion $^{\mathrm{TM}}$ N117 was used to separate the half-cells.

The development of the electrolyte conductivity was used to calculate the SoC during operation. A few electrolyte samples were taken at the very low and very high SoC of positive and negative electrolyte. The vanadium concentration and $\mathrm{SoC}$ of the samples were determined by redox titration [27]. To calculate the SoC of positive and negative electrolyte during the measurements the conductivity and temperature signals were applied to the following empirical equation [28]

$\mathrm{SoC}=\frac{\kappa-C \cdot T-D}{A \cdot T+B}$

where $\kappa$ is the conductivity of the electrolyte, T the temperature of the electrolyte and $A, B, C$ and $D$ are empirical constants. $D$ and $B$ were adapted to fit the values determined by redox titration for each electrolyte.

\section{Model validation}

The first electrolyte samples were taken after the first charging process, which is why this point is the initial state for the model. The tank fill level at this point is defined to be $100 \%$. The positive electrolyte has a vanadium concentration of $1.60 \mathrm{~mol} \mathrm{~L}^{-1}$ and a SoC of $91 \%$, the negative electrolyte has $1.58 \mathrm{~mol} \mathrm{~L}^{-1}$ vanadium and $84 \% \mathrm{SoC}$ at the starting point. In the model the change from charge to discharge or vice versa occurs as soon as one electrolyte reaches a $\mathrm{SoC}$ of $90 \%$ during charging or $10 \%$ during discharging which corresponds sufficiently well with the measured values. In total eight samples were taken: The first sample was taken after the first charging process (cycle 0 ) starting from an electrolyte with an equimolar mixture of $\mathrm{V}^{3+}$ and $\mathrm{VO}^{2+}$. For the next discharging (cycle 0.5) and charging process (cycle 1.0), two more samples from each electrolyte were taken. In total samples were taken at the end of cycle $0,0.5$, 1.0, 4.0, 4.5, 7.5, 8.0 and 10.5. The model was validated by minimizing the differences between the calculated and measured values of SoC, tank fill level and total vanadium concentration $c_{\mathrm{V}}$ in both half-cells. During the validation process (using MATLAB's function "fmincon"), the values of the mass transfer coefficients $k^{\text {eosm }}$ and $v_{H+, \mathrm{H} 2 \mathrm{O}}^{\text {drag }}$ were adjusted (Table 1). The mass transfer coefficients $k_{i}^{\text {ditif }}$ for the vanadium species come from separate own measurements [24] and were regarded as constant. A comparison with literature shows a large variation of values for the vanadium mass transfer coefficient due to crossover. The reason for these differences is presumably the different way and conditions (sulphate and vanadium concentration, test facility) for measuring the diffusion. A common way of determining the diffusion coefficient is utilizing a dialysis cell. The coefficients used in this work, however, were measured using vanadium electrolyte at both sides of the membrane and are therefore relevant for real operating conditions. A comparison of the other mass transport coefficients is not meaningful because these parameters were not used in other studies.

The mass transfer coefficients $k_{i}^{\text {migr }}$ were calculated according to Einstein-Smoluchowski as follows:

$k_{i}^{\mathrm{migr}}=\frac{z_{i} \cdot \mathrm{F} \cdot D_{i}}{\mathrm{R} \cdot \mathrm{T} \cdot d_{\mathrm{Mem}}}$

The comparison of the calculated values with the measurements shows a good agreement as can be seen in Fig. 2. The vanadium concentration in the positive electrolyte decreases during discharge and increases during charge. These concentration shifts differ from results described in other papers $[18,21]$, where the vanadium concentration decreases in the PE during charge and increases during discharge. In total, the vanadium concentration increases in the positive electrolyte, which agrees with the literature. Overall, the tank volume increases in the PT and approaches an almost stationary state. Reverse developments in vanadium concentration and tank fill level can be observed for the negative electrolyte.

Table 1 Mass transfer coefficients used for the mathematical model

\begin{tabular}{llll}
\hline Symbol & Description & Value & Literature \\
\hline$k_{\mathrm{V} 2}^{\text {diff }}$ & Mass transport coefficient due to diffusion of $\mathrm{V}^{2+}\left(\mathrm{m} \mathrm{s}^{-1}\right)$ & $28.7 \times 10^{-9}$ & $34.2 \times 10^{-9}[17], 7.7 \times 10^{-9}[29]$ \\
$k_{\mathrm{V} 3}^{\text {diff }}$ & Mass transport coefficient due to diffusion of $\mathrm{V}^{3+}\left(\mathrm{m} \mathrm{s}^{-1}\right)$ & $9.3 \times 10^{-9}$ & $32.4 \times 10^{-9}[30], 7.1 \times 10^{-9}[29]$ \\
$k_{\mathrm{V} 4}^{\text {diff }}$ & Mass transport coefficient due to diffusion of $\mathrm{VO}^{2+}\left(\mathrm{m} \mathrm{s}^{-1}\right)$ & $19.3 \times 10^{-9}$ & $27.3 \times 10^{-9}[30], 32.3 \times 10^{-9}[29]$ \\
$k_{\mathrm{V} 5}^{\text {diff }}$ & Mass transport coefficient due to diffusion of $\mathrm{VO}_{2}^{+}\left(\mathrm{m} \mathrm{s}^{-1}\right)$ & $4.9 \times 10^{-9}$ & $6.4 \times 10^{-9}[30], 23.5 \times 10^{-9}[29]$ \\
$k_{\mathrm{H} 2 \mathrm{O}}^{\text {diff }}$ & Mass transport coefficient due to diffusion of $\mathrm{H}_{2} \mathrm{O}\left(\mathrm{m} \mathrm{s}^{-1}\right)$ & $3.14 \times 10^{-6}$ & $3.14 \times 10^{-6}[31]$ \\
$k^{\text {eosm } *}$ & Mass transport coefficient due to electro osmosis $\left(\mathrm{m} \mathrm{V}^{-1} \mathrm{~s}^{-1}\right)$ & $3.44 \times 10^{-7}$ & \\
$v_{H+, \mathrm{H} 2 \mathrm{O}}^{\text {drag }} *$ & Amount of water dragged by $\mathrm{H}_{2} \mathrm{O}$ & 1.5 & $2.5[9]$ \\
\hline
\end{tabular}

Parameters adapted during model validation are indicated by $*$ 
Fig. 2 Comparison of measured values with calculated values of a V-concentration, b tank fill level, $\mathbf{c}$ and $\mathbf{d} \mathrm{SoC}$
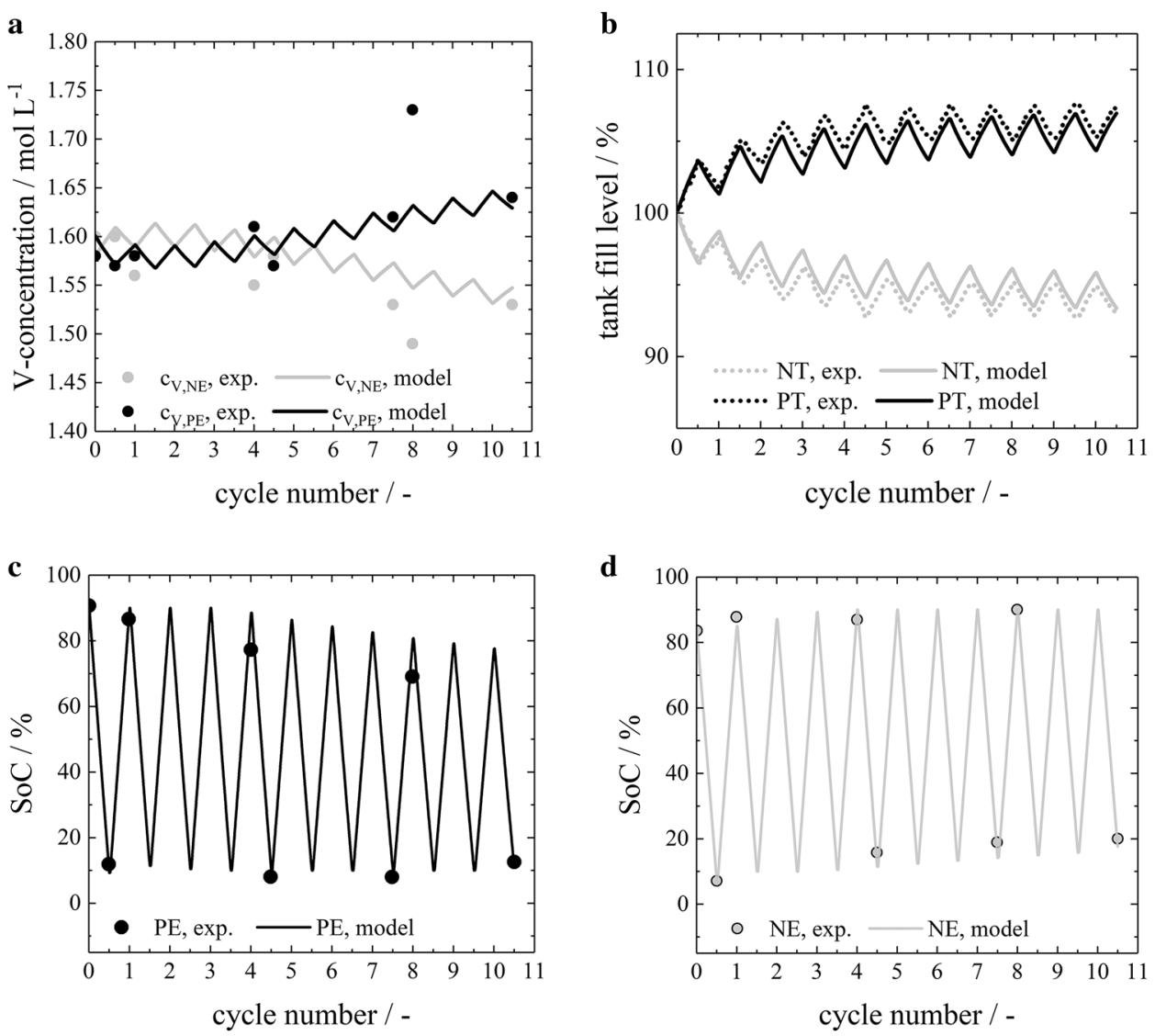

d

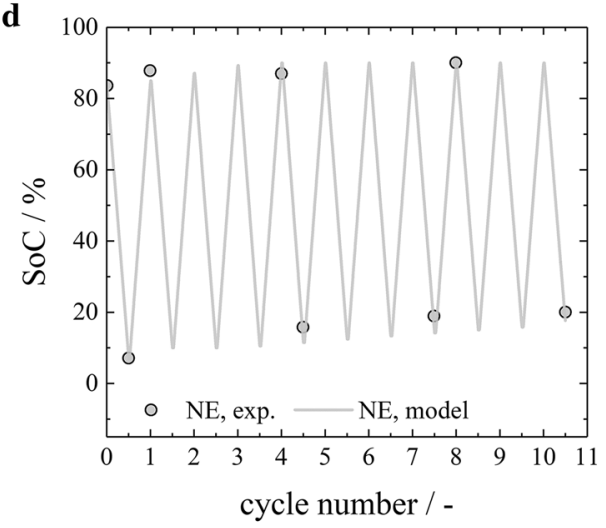

An increase in vanadium concentration and electrolyte volume results in an enrichment of vanadium in the positive electrolyte and otherwise a dilution in the negative electrolyte. As a consequence of the larger vanadium crossover towards the PE and therefore a discharge of the electrolyte and the enrichment of vanadium, the PE does not reach the high SoC of $90 \%$ after only a few cycles. Whereas the negative electrolyte does not reach the low SoC of $10 \%$ due to the fast discharge of the positive electrolyte.
For the first charge-discharge cycle, the distribution of the vanadium fluxes due to the three crossover mechanisms is shown in Fig. 3. Unlike modelling results in other papers [17, 18, 18, 21], our analysis indicates that migration makes a major part of the vanadium crossover during the discharge process. On the basis of the measurement results, the increase of the vanadium amount in the PE combined with the course of the tank fill level can only be described with these high impacts of migration of $\mathrm{V}^{2+}$ and $\mathrm{V}^{3+}$. To verify these parameters, further measurements are required in which the individual crossover mechanisms can separated from the other mechanisms.
Fig. 3 Distribution of vanadium crossover fluxes via diffusion, electro osmosis and migration for the first cycle during a discharge and $\mathbf{b}$ charge a

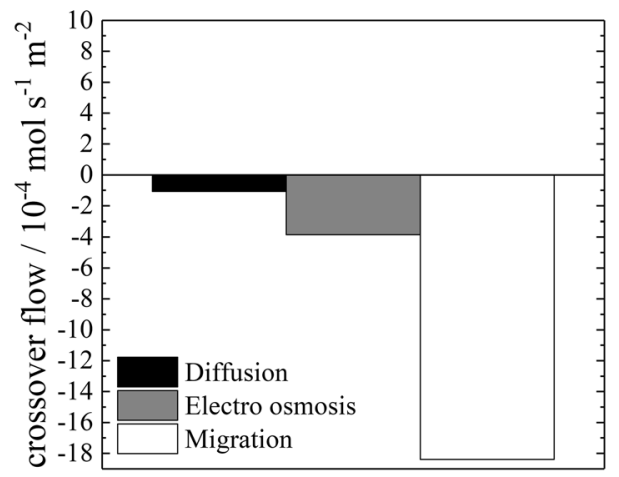

b

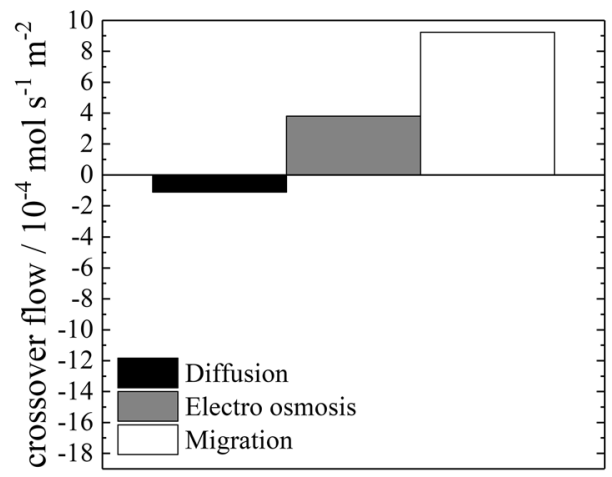




\section{Simulation results and discussion}

With the validated model, the system behaviour was calculated for 200 cycles. A rapid decrease of the DoD (ratio of the actual capacity and the theoretically available capacity) with each cycle can be observed (see Fig. 4). The reason for the capacity loss is the dilution of vanadium in the negative electrolyte tank. In Fig. 4 it can be seen that the tank fill level decreases in the negative storage tank and that the vanadium concentration decreases at the same time.

As a method for capacity rebalancing, a continuous overflow from the PT to the NT was implemented to the model. Due to the overflow, the total vanadium amount in the NT increases if the overflow rate is large enough. At the same time discharge reactions take place and the sulphate amount increases in the NT. The system behaviour was analysed for different overflow rates. The DoD as a function of the cycle number for these calculations is shown in Figs. 5 and 6. The simulation results shown in Fig. 5 reveal that a small overflow rate of $0.25 \mathrm{~mL} \mathrm{~h}^{-1}$ results already in a rise of the DoD compared to an operation without overflow. A higher overflow rate of $0.75 \mathrm{~mL} \mathrm{~h}^{-1}$ shows a significantly better performance until cycle 200. A maximum of the DoD at cycle 80 can be observed. After reaching this point, the DoD

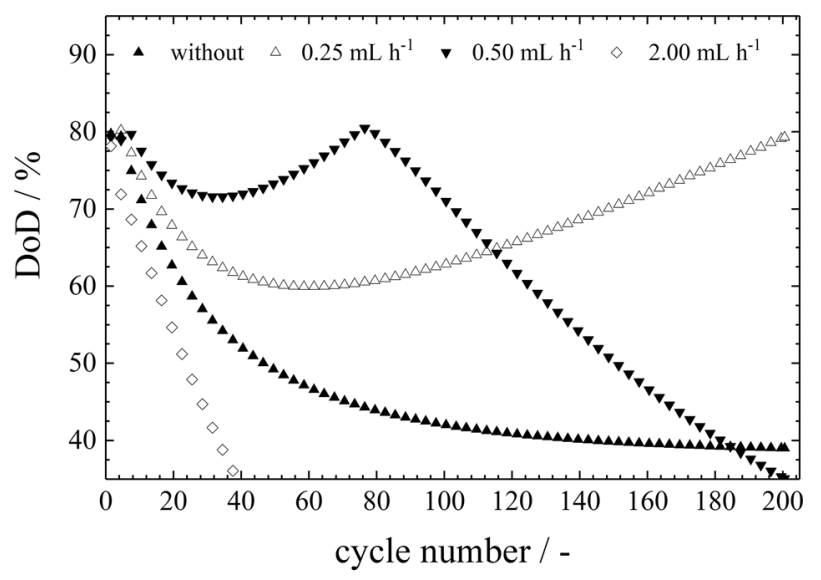

Fig. 5 DoD development for different overflow rates over 200 cycles

decreases continuously. However, an even higher overflow rate of $2 \mathrm{~mL} \mathrm{~h}^{-1}$ leads to a high self-discharge of the NE which results in a very fast decrease of the DoD. In this case, the mass of vanadium flowing from PT to NT is too high for a reasonable operation, which results in rapid attainment of both, the low SoC limit in the negative electrolyte and the high $\mathrm{SoC}$ limit in the positive electrolyte.
Fig. 4 Modelling results for the system behaviour during 200 charge/discharge cycles; a tank fill level, $\mathbf{b}$ total vanadium concentration, $\mathbf{c}$ minimum and maximum SoC, $\mathbf{d}$ DoD

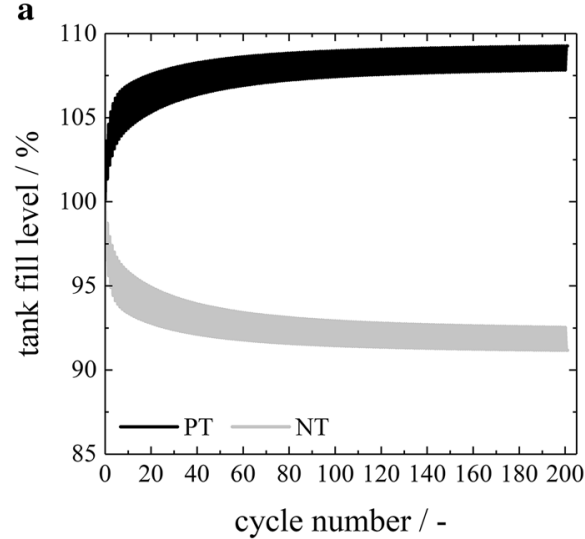

c

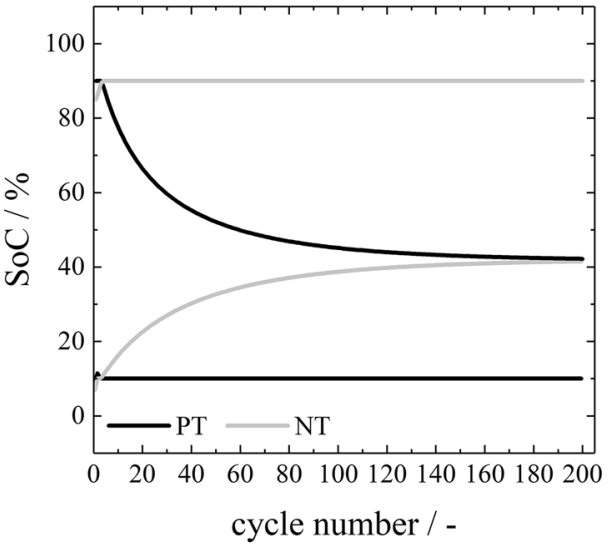

b

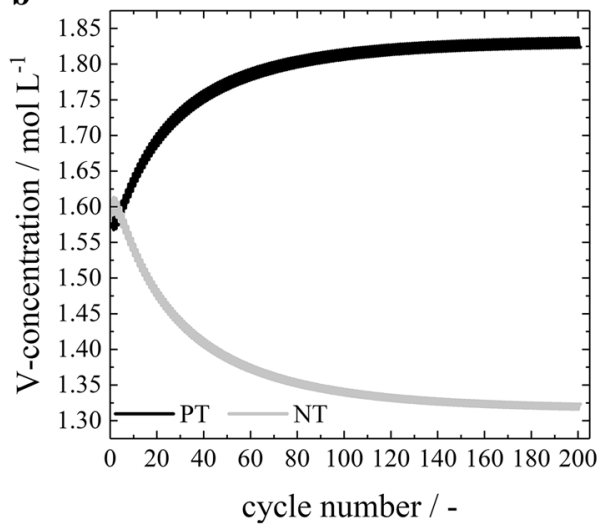

d

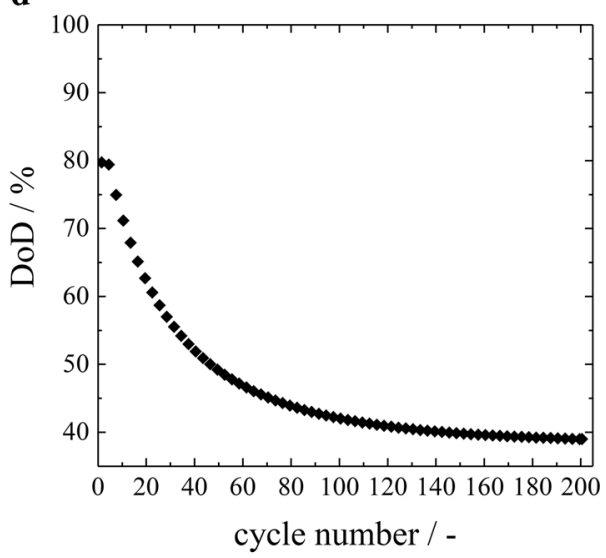




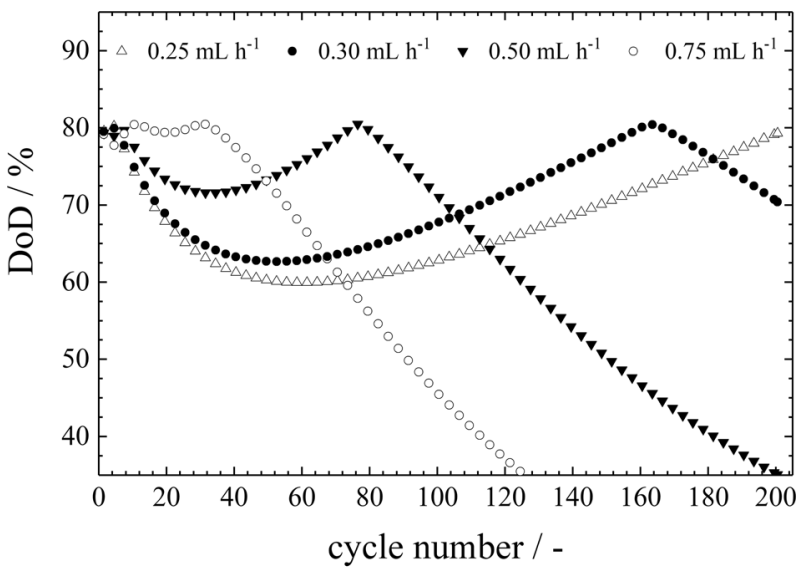

Fig. 6 DoD development for selected overflow rates over 200 cycles

In a range of overflow rates between 0.25 and $0.75 \mathrm{~mL} \mathrm{~h}^{-1}$, the performance improvement reaches an optimum (see Fig. 6). Overall, the DoD profiles show a similar course. For these overflow rates the DoD decreases during the first cycles. The reason for this decline is that the crossover of vanadium from NE to PE is initially bigger than the vanadium amount coming from PT to NT due to the continuous overflow. Depending on the overflow rate, the equivalence of vanadium mass flow due to crossover and overflow is reached at varying times. For an overflow rate of $0.25 \mathrm{~mL} \mathrm{~h}^{-1}$ the equilibrium is reached after approximately 200 cycles and for $0.5 \mathrm{~mL} \mathrm{~h}^{-1}$ already after 76 cycles. From this point the amount of vanadium flowing from PT to NT is larger than the vanadium transport through the membrane. At the same time, the overflow leads to a decrease of SoC in the negative electrolyte. One can see that the DoD rises after only a few cycles after the initial decrease for an overflow rate of $0.75 \mathrm{~mL} \mathrm{~h}^{-1}$. This is because the discharge of the negative electrolyte enables the utilization of the entire SoC spectrum for certain cycles. The higher the overflow rate the earlier the DoD decreases again due to a strong discharge of the negative electrolyte.

However, not only maintaining the DoD is important for the battery performance. Due to the overflow, the sulphate concentration increases and the vanadium concentration decreases continuously in the NT while the sulphate concentration decreases and the vanadium concentration increases in the PT, respectively. The electrolyte, however, is only stable in a small range of vanadium and sulphate concentrations. To be sure that no precipitation takes place, a maximum concentration of $2 \mathrm{~mol} \mathrm{~L}^{-1}$ for vanadium and a minimum concentration of $3.3 \mathrm{~mol} \mathrm{~L}^{-1}$ for sulphate were selected as limits [32]. For overflow rates in the range from 2.0 to $2.7 \mathrm{~mL} \mathrm{~h}^{-1}$, the sulphate concentration does not fall below the limit of $3.3 \mathrm{~mol} \mathrm{~L}{ }^{-1}$. The development of the vanadium and sulphate concentration in the $\mathrm{PE}$ is shown in
Fig. 7 Vanadium concentration development in the PE versus cycle number for an overflow rate of $\mathbf{a} 0.25 \mathrm{~mL} \mathrm{~h}^{-1}$, b $0.30 \mathrm{~mL} \mathrm{~h}^{-1}, \mathbf{c} 0.50 \mathrm{~mL} \mathrm{~h}^{-1}$ and d $0.75 \mathrm{~mL} \mathrm{~h}^{-1}$
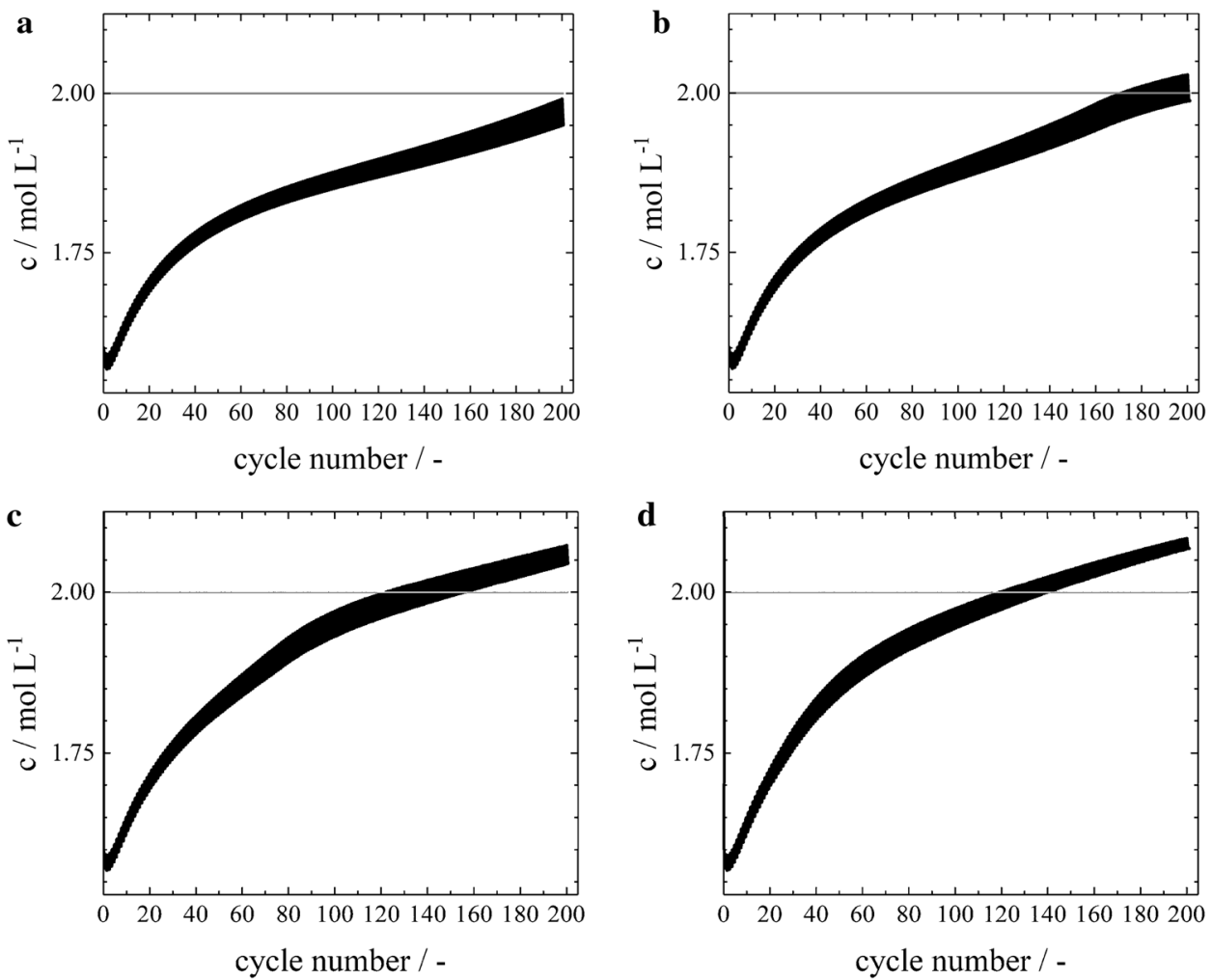
Fig. 8 Results for a dynamic overflow rate from PT to NT a DoD and overflow, $\mathbf{b}$ vanadium concentration in PT

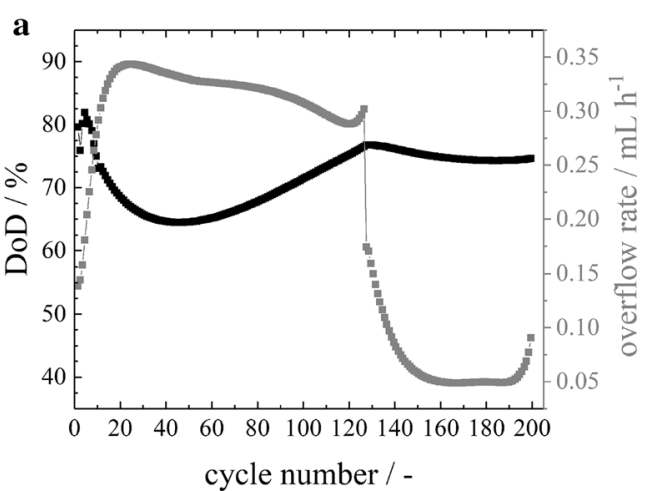

Fig. 7 for the considered overflow rates. The concentration limit is plotted as grey solid line. It can be seen, that the vanadium concentration exceeds the limit of $2 \mathrm{~mol} \mathrm{~L}^{-1}$ after 150 cycles for an overflow rate of $0.5 \mathrm{~mL} \mathrm{~h}^{-1}$ and after 135 cycles for an overflow rate of $0.75 \mathrm{~mL} \mathrm{~h}^{-1}$. Regarding both, the DoD and the electrolyte stability, the battery shows the best performance with an overflow rate of $0.3 \mathrm{~mL} \mathrm{~h}^{-1}$ since the DoD is higher until cycle 180 compared to an overflow rate of $0.25 \mathrm{~mL} \mathrm{~h}^{-1}$. As a result of the limited electrolyte stability, the electrolytes of both tanks need to be remixed after exceeding the vanadium or sulphate concentration limit. Remixing results in an equimolar mixture of $\mathrm{V}^{3+}$ and $\mathrm{VO}^{2+}$, which corresponds to a $\mathrm{SoC}$ of $-50 \%$, and a balanced sulphate concentration of $4 \mathrm{~mol} \mathrm{~L}^{-1}$ in each tank. The remixing requires a certain time during which the battery cannot be used and additionally, energy is needed to charge the electrolyte from the $\mathrm{SoC}$ of $-50 \%$ after remixing to $0 \%$. This energy cannot be regained from the system by discharging. Prior to remixing the system would certainly be discharged to a level as low as possible to reduce losses by the remixing process. Since we set the minimum SoC to $10 \%$ during charge-discharge cycling, we can assume a SoC of $10 \%$ for both electrolytes before remixing. This would lead to $60 \%$ of recharging energy demand to bring the SoC from $-50 \%$ back to $10 \%$ as it was before remixing. The recharging energy demand is necessary after every $175^{\text {th }}$ cycle and corresponds to an additional theoretical energy loss of $0.3 \%$ per cycle (for an overflow of $0.3 \mathrm{~mL} \mathrm{~h}^{-1}$ ). For another exemplary SoC of $30 \%$ before mixing, an additional energy loss of $0.5 \%$ would occur.

A constant overflow is clearly not sufficient to ensure a permanently stable operation, thus a better solution for maintaining the DoD would probably be an adaption of the overflow rate with time. In this way, the battery could be operated as long and as efficiently as possible maintaining a high DoD and stable electrolytes. Comparing the DoD developments in Fig. 6, a high overflow rate at the beginning with a decrease after a certain number of cycles will give the best result regarding DoD and electrolyte stability.
Therefore, a dynamic electrolyte overflow was determined for 200 cycles. The overflow rates are adapted after each charge and discharge cycle in such a way that the sum of all DoDs over the full set of cycles reaches a maximum and that the concentration limits for vanadium and sulphate are maintained for at least 200 cycles (using MATLAB's function "fminfun"). The resulting overflow rates are shown in Fig. 8. It can be seen, that the overflow rate rises significantly from a value of $0.14 \mathrm{~mL} \mathrm{~h}^{-1}$ to $0.35 \mathrm{~mL} \mathrm{~h}^{-1}$ in the first few cycles. This is followed by a slow decrease of the overflow rate. After 120 cycles a rapid decrease can be seen, so that after about 150 cycles a low overflow rate of less than $0.1 \mathrm{~mL} \mathrm{~h}^{-1}$ is reached. The DoD decreases from $80 \%$ in the first cycles to a value of $64 \%$ after 40 cycles. The DoD increases afterwards again. The increase of the DoD is ended by the rapid decrease of the overflow after 120 cycles. Afterwards the discharge depth decreases slightly at an almost stable plateau. The vanadium concentration limit of $2 \mathrm{~mol} \mathrm{~L}^{-1}$ is reached after 200 cycles, so a remixing of electrolytes would probably be needed after operating of a few more cycles.

\section{Conclusion}

In this work, the crossover processes through a cation exchange membrane in a VFB during charge-discharge cycles have been simulated and validated with own measurements. The model describes the crossover mechanisms diffusion, migration and electro osmosis for the vanadium species and water using basic mass transport equations. The simulation results show that the DoD decreases rapidly with each cycle when using the membrane Nafion ${ }^{\mathrm{TM}}$ N117 from Chemours. On this account, a continuous electrolyte overflow from PT to NT was implemented into the model. The battery performance, characterised by the DoD, improves strongly using a continuous electrolyte overflow from PT to NT in a certain range of overflow flow rates. However, the electrolyte stability is a limiting factor in an operating 
VFB because the vanadium and sulphate concentrations in the electrolytes are influenced by the overflow. A constant overflow rate of $0.3 \mathrm{~mL} \mathrm{~h}^{-1}$ shows the best compromise between battery performance and electrolyte stability for the test facility used. A remixing process, however, is crucial for a reasonable long-term operation of the VFB with the chosen membrane. When considering a dynamic overflow, it is possible to reach the maximum DoD over a given number of cycles (200 in this work) while the limits of concentration are not exceeded. Further optimization potential of the dynamic overflow can be expected for controlled overflow only during low states of charge, since this would lower self-discharge effects distinctly. Such further optimization strategies could be combined with concentration-dependent overflow control algorithms and should be the scope of further work. However, our results for continuous and dynamic overflow rates show that the crossover of this membrane is too large for an efficient operation of a VFB and therefore the use of other membranes with a significantly lower crossover and even further optimized balancing procedures would be more reasonable [29, 33-35].

Acknowledgements The authors gratefully acknowledge thyssenkrupp Industrial Solutions AG for financial support and the Research Center for Energy Storage Technologies of Clausthal University of Technology for technical assistance during this project.

Funding Open Access funding enabled and organized by Projekt DEAL.

Open Access This article is licensed under a Creative Commons Attribution 4.0 International License, which permits use, sharing, adaptation, distribution and reproduction in any medium or format, as long as you give appropriate credit to the original author(s) and the source, provide a link to the Creative Commons licence, and indicate if changes were made. The images or other third party material in this article are included in the article's Creative Commons licence, unless indicated otherwise in a credit line to the material. If material is not included in the article's Creative Commons licence and your intended use is not permitted by statutory regulation or exceeds the permitted use, you will need to obtain permission directly from the copyright holder. To view a copy of this licence, visit http://creativecommons.org/licenses/by/4.0/.

\section{References}

1. Tang A, Bao J, Skyllas-Kazacos M (2011) Dynamic modelling of the effects of ion diffusion and side reactions on the capacity loss for vanadium redox flow battery. J Power Sources 196(24):1073710747. https://doi.org/10.1016/j.jpowsour.2011.09.003

2. Sun J, Shi D, Zhong H et al (2015) Investigations on the selfdischarge process in vanadium flow battery. J Power Sources 294:562-568. https://doi.org/10.1016/j.jpowsour.2015.06.123

3. Agar E, Knehr KW, Chen D et al (2013) Species transport mechanisms governing capacity loss in vanadium flow batteries: comparing Nafion $(\mathrm{R})$ and sulfonated Radel membranes. Electrochim Acta 98:66-74. https://doi.org/10.1016/j.electacta.2013.03.030
4. Darling RM, Weber AZ, Tucker MC et al (2015) The influence of electric field on crossover in redox-flow batteries. J Electrochem Soc 163(1):A5014-A5022

5. Oh K, Won S, Ju H (2015) A comparative study of species migration and diffusion mechanisms in all-vanadium redox flow batteries. Electochim Acta 181:238-247. https://doi.org/10.1016/j.elect acta.2015.03.012

6. Knehr KW, Kumbur EC (2012) Role of convection and related effects on species crossover and capacity loss in vanadium redox flow batteries. Electrochem Commun 23:76-79. https://doi.org/ 10.1016/j.elecom.2012.07.008

7. Ashraf Gandomi Y, Aaron DS, Mench MM (2016) Coupled membrane transport parameters for ionic species in all-vanadium redox flow batteries. Electrochim Acta 218:174-190. https://doi.org/10. 1016/j.electacta.2016.09.087

8. Agar E, Benjamin A, Dennison CR et al (2014) Reducing capacity fade in vanadium redox flow batteries by altering charging and discharging currents. J Power Sources 246:767-774. https://doi. org/10.1016/j.jpowsour.2013.08.023

9. Sun CX, Chen J, Zhang HM et al (2010) Investigations on transfer of water and vanadium ions across Nafion membrane in an operating vanadium redox flow battery. J Power Sources 195(3):890897. https://doi.org/10.1016/j.jpowsour.2009.08.041

10. Luo QT, Li LY, Nie ZM et al (2012) In-situ investigation of vanadium ion transport in redox flow battery. J Power Sources 218:15-20. https://doi.org/10.1016/j.jpowsour.2012.06.066

11. Sing DD, Meyers JP (2013) Direct measurement of vanadium crossover in an operating vanadium redox flow battery. Electrochem Soc 50(45):61-72. https://doi.org/10.1149/05045.0061ecst

12. You D, Zhang H, Sun C et al (2011) Simulation of the self-discharge process in vanadium redox flow battery. J Power Sources 196(3):1578-1585. https://doi.org/10.1016/j.jpowsour.2010.08. 036

13. Sukkar T, Skyllas-Kazacos M (2003) Water transfer behaviour across cation exchange membranes in the vanadium redox battery. J Membr Sci 222(1-2):235-247. https://doi.org/10.1016/S03767388(03)00309-0

14. Wang K, Liu Le, Xi J et al (2017) Reduction of capacity decay in vanadium flow batteries by an electrolyte-reflow method. J Power Sources 338:17-25. https://doi.org/10.1016/j.jpowsour.2016.11. 031

15. Rudolph S, Schröder U, Bayanov IM (2013) On-line controlled state of charge rebalancing in vanadium redox flow battery. $\mathrm{J}$ Electroanal Chem 703(Supplement C):29-37. https://doi.org/10. 1016/j.jelechem.2013.05.011

16. Zhang Y, Liu Le, Xi J et al (2017) The benefits and limitations of electrolyte mixing in vanadium flow batteries. Appl Energy 204:373-381. https://doi.org/10.1016/j.apenergy.2017.07.049

17. Boettcher PA, Agar E, Dennison CR et al (2016) Modeling of ion crossover in vanadium redox flow batteries: a computationallyefficient lumped parameter approach for extended cycling. J Electrochem Soc 163(1):A5244-A5252. https://doi.org/10.1149/2. 0311601jes

18. Knehr KW, Agar E, Dennison CR et al (2012) A transient vanadium flow battery model incorporating vanadium crossover and water transport through the membrane. J Electrochem Soc 159(9):A1446-A1459. https://doi.org/10.1149/2.017209jes

19. Skyllas-Kazacos M, Goh L (2012) Modeling of vanadium ion diffusion across the ion exchange membrane in the vanadium redox battery. J Membr Sci 399-400:43-48. https://doi.org/10.1016/j. memsci.2012.01.024

20. Won S, Oh K, Ju H (2015) Numerical analysis of vanadium crossover effects in all-vanadium redox flow batteries. Electrochim Acta 177:310-320. https://doi.org/10.1016/j.electacta.2015. 01.166 
21. Yang X-G, Ye Q, Cheng P et al (2015) Effects of the electric field on ion crossover in vanadium redox flow batteries. Appl Energy 145(Supplement C):306-319. https://doi.org/10.1016/j.apenergy. 2015.02.038

22. Crothers AR, Darling RM, Kushner DI et al (2020) Theory of multicomponent phenomena in cation-exchange membranes: Part III. Transport in vanadium redox-flow-battery separators. J Electrochem Soc 167(1):13549. https://doi.org/10.1149/1945-7111/ ab6725

23. Kim DK, Yoon SJ, Kim S (2020) Transport phenomena associated with capacity loss of all-vanadium redox flow battery. Int J Heat Mass Transf 148:119040. https://doi.org/10.1016/j.ijheatmasstrans fer.2019.119040

24. Schafner K (2020) Modellierung der Crossover-Prozesse und Entwicklung von Kapazitatsausgleichsstrategien zurBetriebsoptimierung von Vanadium-Redox-Flow-Batterien. Dissertation, TU Clausthal

25. Schafner K, Becker M, Turek T (2019) Membrane resistance of different separator materials in a vanadium redox flow battery. $\mathrm{J}$ Membr Sci 586:106-114. https://doi.org/10.1016/j.memsci.2019. 05.054

26. Watt-Smith MJ, Ridley P, Wills RGA et al (2013) The importance of key operational variables and electrolyte monitoring to the performance of an all vanadium redox flow battery. J Chem Technol Biotechnol 88(1):126-138. https://doi.org/10.1002/jctb.3870

27. Treadwell WD, Nieriker R (1941) Über einige potentiometrische Folgetitrationen von Verbindungen des Wolframs und Molybdäns neben solchen des Vanadiums und des Eisens. Helv Chim Acta 24:1098-1105

28. Corcuera S, Skyllas-Kazacos M (2012) State-of-charge monitoring and electrolyte rebalancing methods for the vanadium redox flow battery. Eur Chem Bull 1:511-519

29. Prifti H, Parasuraman A, Winardi S, Lim TM, Skyllas-Kaza$\cos$ M (2012) Membranes for redox flow battery applications.
Membranes 2:275-306. https://doi.org/10.3390/membranes2 020275

30. Xi J, Wu Z, Teng X et al (2008) Self-assembled polyelectrolyte multilayer modified Nafion membrane with suppressed vanadium ion crossover for vanadium redox flow batteries. J Mater Chem 18(11):1232-1238. https://doi.org/10.1039/B718526J

31. Shah AA, Watt-Smith MJ, Walsh FC (2008) A dynamic performance model for redox-flow batteries involving soluble species. Electrochim Acta 53(27):8087-8100. https://doi.org/10.1016/j. electacta.2008.05.067

32. Kazacos M, Cheng M, Skyllas-Kazacos M (1990) Vanadium redox cell electrolyte optimization studies. J Appl Electrochem 20(3):463-467. https://doi.org/10.1007/BF01076057

33. Reed D, Thomsen E, Wang W et al (2015) Performance of Nafion ${ }^{\circledR}$ N115, Nafion ${ }^{\circledR}$ NR-212, and Nafion ${ }^{\circledR}$ NR-211 in a 1 $\mathrm{kW}$ class all vanadium mixed acid redox flow battery. J Power Sources 285:425-430. https://doi.org/10.1016/j.jpowsour.2015. 03.099

34. Choi HS, Oh YH, Ryu CH et al (2014) Characteristics of the allvanadium redox flow battery using anion exchange membrane. J Taiwan Inst Chem E 45(6):2920-2925. https://doi.org/10.1016/j. jtice.2014.08.032

35. Dai WJ, Yu LH, Li ZH et al (2014) Sulfonated poly(ether ether ketone)/graphene composite membrane for vanadium redox flow battery. Electrochim Acta 132:200-207. https://doi.org/10.1016/j. electacta.2014.03.156

Publisher's Note Springer Nature remains neutral with regard to jurisdictional claims in published maps and institutional affiliations. 